\title{
Ahmed glaucoma valve implant: surgical technique and complications
}

This article was published in the following Dove Press journal:

Clinical Ophthalmology

17 February 2017

Number of times this article has been viewed

Ivano Riva'

Gloria Roberti'

Francesco Oddone'

Anastasios GP Konstas ${ }^{2}$

Luciano Quaranta ${ }^{3}$

'IRCCS "Fondazione GB Bietti per l'Oftalmologia", Rome, Italy;

${ }^{2}$ Ist University Department of Ophthalmology, Glaucoma Unit, AHEPA Hospital, Thessaloniki, Greece; ${ }^{3}$ Department of Medical and Surgical Specialties, Section of Ophthalmology, University of Brescia, Brescia, Italy
Correspondence: Luciano Quaranta Divisione di Oculistica, Azienda Ospedaliera Spedali Civili di Brescia, Piazzale Spedali Civili, I, 25 I 23 Brescia, Italy

$\mathrm{Tel}+390303995847$

Fax +39030396622

Email luciano.quaranta@unibs.it

\begin{abstract}
Implantation of Ahmed glaucoma valve is an effective surgical technique to reduce intraocular pressure in patients affected with glaucoma. While in the past, the use of this device was reserved to glaucoma refractory to multiple filtration surgical procedures, up-to-date mounting experience has encouraged its use also as a primary surgery for selected cases. Implantation of Ahmed glaucoma valve can be challenging for the surgeon, especially in patients who already underwent previous multiple surgeries. Several tips have to be acquired by the surgeon, and a long learning curve is always needed. Although the valve mechanism embedded in the Ahmed glaucoma valve decreases the risk of postoperative hypotony-related complications, it does not avoid the need of a careful follow-up. Complications related to this type of surgery include early and late postoperative hypotony, excessive capsule fibrosis around the plate, erosion of the tube or plate edge, and very rarely infection. The aim of this review is to describe surgical technique for Ahmed glaucoma valve implantation and to report related complications.
\end{abstract}

Keywords: glaucoma, surgical technique, glaucoma drainage devices, Ahmed glaucoma valve, complications

\section{Introduction}

Glaucoma, the second leading cause of blindness in the world, is defined as a chronic optic neuropathy, linked to progressive visual field defects. In 2013, the total number of people (aged 40-80 years) with glaucoma worldwide was estimated to be 64.3 million. ${ }^{1}$ Asia alone accounted for $\sim 60 \%$ of the world's total glaucoma cases ( 39 million), and Africa had the second highest number of cases with 8.3 million (13\%). Europe and North America had 6.77 and 3.36 million cases, respectively. ${ }^{1}$

Although many risk factors have been described for glaucoma development and progression (intraocular pressure $[\mathrm{IOP}],{ }^{2-5}$ age, ${ }^{3-5}$ genetic predisposition, ${ }^{6}$ and vascular parameters $^{7-9}$ ), lowering IOP is the only scientifically demonstrated method to slow the progression of the disease. The Early Manifest Glaucoma Trial has demonstrated a $10 \%$ reduction of the risk of glaucoma progression with each $\mathrm{mmHg}$ of IOP decrease from baseline (hazard ratio $[\mathrm{HR}]=0.90$ per $\mathrm{mmHg}$ decrease; $95 \%$ confidence interval [CI], 0.86-0.94). ${ }^{2}$ Similarly, in the UK Glaucoma Treatment Study, a 19\% decrease of the risk of visual field progression has been found with each $\mathrm{mmHg}$ reduction from baseline. ${ }^{10}$

IOP reduction in glaucoma patients can be achieved with medical, laser, or surgical therapy. ${ }^{11}$ Medical therapy is generally the first step, due to the low rate of side effects. However, when target IOP is not achievable, laser and/or surgery should be chosen. ${ }^{12}$ Trabeculectomy, which was first described by Cairns in $1968,{ }^{13}$ is considered the surgical "gold standard" for primary open-angle glaucoma and primary angle-closure glaucoma. 
Variable success rates for trabeculectomy have been reported in literature. Although success rates are high in the first few years after surgery $(70 \%-92 \%),{ }^{14-16}$ they tend to decrease with time (42\%-90\%), ${ }^{17-20}$ especially in secondary glaucomas. ${ }^{21-24}$ Moreover, as trabeculectomy involves anterior subconjunctival space, it is largely influenced by healing processes, and healing modulation with intraoperative and postoperative antimetabolites (ie, mitomycin C [MMC] and 5-fluorouracil $[5 \mathrm{FU}])$ is a fundamental part of the procedure.

Aqueous shunts are a reliable alternative to trabeculectomy. ${ }^{25}$ Conceptually, shunting aqueous humor $(\mathrm{AH})$ to the posterior subconjunctival space may avoid healing issues, especially in patients who have already undergone previous glaucoma surgeries or conjunctival manipulation. The first successful prototype of aqueous shunt was the Molteno implant, followed by Krupin, Ahmed, and Baerveldt implant. While in the past, these devices were usually reserved as a second choice surgery, today mounting experience has encouraged their use also as a primary surgery. ${ }^{26}$ The aim of this review is to evaluate surgical technique and complications of Ahmed glaucoma valve (AGV) implant.

\section{AGV: device description and technical data}

First attempts at developing a glaucoma drainage implant were published in $1906,{ }^{27}$ even if the first device currently in use was developed by Molteno et al only in $1976 .{ }^{28}$ Molteno device offers no resistance to $\mathrm{AH}$ outflow and initially was burdened by a high rate of complications, such as hypotony, shallow anterior chamber (AC), choroidal effusion, and choroidal detachment. ${ }^{26}$ Implants with an embedded valve mechanism were developed as an attempt at overwhelming these complications. In 1976, Krupin designed a pressure-sensitive unidirectional valve to provide filtration restriction. ${ }^{29}$ Its passive mechanism contemplates a silastic tube, whose distal end is sealed and contains several horizontal and vertical slits. Krupin implant is designed to open when IOP is $>11 \mathrm{mmHg}^{29,30}$

AGV provides a more complex mechanism to control AH outflow. It was developed by Mateen Ahmed and was approved by the Food and Drug Administration in 1993. ${ }^{31}$ It consists of 3 parts (Figure 1A): 1) a plate, in medical grade silicone, polypropylene, or porous polyethylene, depending on the model; 2) a drainage tube in medical grade silicone; and 3) a valve mechanism in medical grade silicone. Polypropylene is a rigid plastic, not flexible and highly resistant to torsional forces, whereas silicone is a flexible rubber.

The adult model (S2) of AGV provides $180 \mathrm{~mm}^{2}$ of total plate area, whereas the pediatric one (S3) has a total area of $96 \mathrm{~mm}^{2}$. Obviously, a smaller plate facilitates positioning in infants and subjects with a small eye. A variant of the device with 2 plates (total filtration area: $360 \mathrm{~mm}^{2}$ ), and one with a clip for pars plana tube insertion have been also designed (Table 1).

The M4 AGV model, recently introduced, is a modified AGV S2 containing identical valve mechanism, but with a case made of porous high-density polyethylene (Medpor; Porex, Atlanta, GA, USA; subsequently, Stryker Corp., Kalamazoo, MI, USA). ${ }^{32}$ Total plate area is $160 \mathrm{~mm}^{2}$, not including the surface area of pores. The pores may facilitate fibrotic and vascular ingrowth and increase resistance to infection, exposure, extrusion, and mechanical deformation. ${ }^{32-34}$ In animal models, this new implant behaved as a variable resistor with higher resistance at low flow rates and lower resistance at high flow rates. ${ }^{35}$ These results support the idea that porous biomaterial may improve hydraulic conductivity of the capsule.
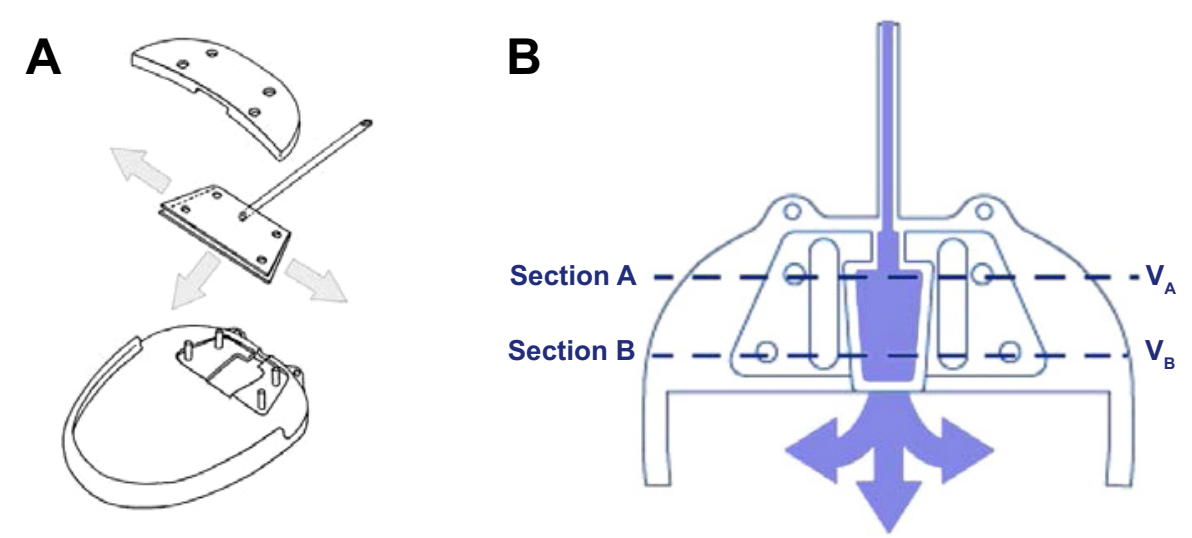

Figure I Ahmed glaucoma valve implant.

Notes: (A) Ahmed glaucoma valve implant components; (B) Ahmed glaucoma valve mechanism. $\vee_{A}$ presented as velocity of fluid flowing in section $A$. $V_{B}$ presented as velocity of fluid flowing in section $B$. 
Table I Ahmed glaucoma valve implant available models

\begin{tabular}{llll}
\hline Type & Model & Size $\left(\mathbf{m m}^{2}\right)$ & Material (plate) \\
\hline Single plate & S2 & 184 & Polypropylene \\
Pediatric size & S3 & 96 & Polypropylene \\
Double plate & BI & 364 & Polypropylene \\
Single plate & FP7 & 184 & Silicone \\
Pediatric size & FP8 & 96 & Silicone \\
Double plate & FXI & 364 & Silicone \\
Single plate & M4 & 160 & Polyethylene \\
Pars plana & PS2 & 184 & Polypropylene \\
Pars plana (pediatric) & PS3 & 96 & Polypropylene \\
Pars plana & PC7 & 184 & Silicone \\
Pars plana (pediatric) & PC8 & 96 & Silicone \\
\hline
\end{tabular}

Valve mechanism of AGV consists of thin silicone elastomer membranes, which are $8 \mathrm{~mm}$ long and $7 \mathrm{~mm}$ wide and create a Venturi-shaped chamber. The membranes are pretensioned to open and close in response to IOP variations, in the range of 8-12 mmHg. ${ }^{31}$ After implantation, AH flows slowly and continuously into the trapezoidal chamber of the valve (Figure 1B). As the pressure reaches the preset threshold value, the valve opens, thus decreasing the IOP. As the inlet cross-section of the chamber is wider than the outlet, a pressure differential is created across the chamber. This pressure differential enables the valve to remain open even with a small pressure differential between the AC and the subconjunctival spaces surrounding the device. In order for Bernoulli's equation to be satisfied (fluid flowing into section A = fluid flowing out of section B, Figure 1B), the fluid's velocity has to increase as it leaves the chamber through the drainage tube. This increased velocity and the nonobtrusive flow account for better evacuation and smaller valve friction. The tension in the silicone membranes helps to reduce hypotony by closing after the pressure has decreased to normal level again.

\section{Surgical technique}

$\mathrm{AGV}$ is designed to guarantee no manipulation during the surgical procedure (ie, no restrictive methods to limit $\mathrm{AH}$ filtration). The implant should be examined for integrity and primed before implantation. Priming is performed by using a $26 \mathrm{G}$ cannula, injecting $\sim 1 \mathrm{cc}$ of balanced salt solution (BSS) or sterile water through the drainage tube. Functionality of the implant is demonstrated by BSS flow through the plate. ${ }^{31}$

Surgical technique for AGV implantation consists of a fornix-based or limbal-based conjunctival incision to create a conjunctival flap between 2 recti muscles, generally in the superotemporal quadrant. As much as possible, Tenon's capsule is dissected from the episclera and episcleral vessels are gently cauterized. The technique does not require recti muscles isolation.

Body implant is positioned $8-10 \mathrm{~mm}$ from the limbus, outside limbal healing space. The plate is then sutured to the sclera with a 9.0 or 10.0 nylon suture. The drainage tube is trimmed to permit a $2-3 \mathrm{~mm}$ insertion in the $\mathrm{AC}$ and is bevel cut to an angle of $30^{\circ}$, to facilitate AC entering. An AC paracentesis is performed, and viscoelastic substance is injected to increase spaces. The AC is then entered 1-3 mm posteriorly to the corneoscleral limbus with a $22-23 \mathrm{G}$ needle. The needle tract is anterior and parallel to the plane of the iris. The tube, which is trimmed so that the bevel faces to the corneal endothelial surface, is inserted into the AC through the needle tract. Care must be taken at this point to ensure that the drainage tube does not contact iris or corneal endothelium after insertion.

An "hangback" technique has been recently proposed to reduce tissue manipulation and facilitate plate insertion during AGV implantation. ${ }^{36}$ According to this technique, the plate is not sutured to the sclera and is allowed to "hang" from the tube, which is anchored to the sclera $6-7 \mathrm{~mm}$ from the limbus, using a 6.0 vicryl suture. Despite initial results for this technique are promising, more extensive research is needed. ${ }^{36}$

In patients with a previous vitrectomy, implant's tube can be inserted in vitreous cavity, avoiding complications that can arise from the presence of the tube in the AC. In this case, a pars plana clip is used to secure the tube to the sclera and to give the tube a suitable angle. The clip is anchored to the sclera with a 9.0 or 10.0 nylon suture.

The drainage tube and eventually the pars plana clip are covered with a piece of preserved, donor sclera, pericardium, cornea, or other suitable patch graft material, which is sutured to the sclera. Alternatively, a two-third thickness limbus scleral flap is created, and the tube is inserted into the AC through a needle tract under the flap. The flap should be closely sutured to avoid peritubular leakage of $\mathrm{AH}$.

In the final step, conjunctiva is anchored to the limbus with adsorbable/nonadsorbable sutures. Optionally, a subconjunctival injection of corticosteroids and antibiotics is performed at the end of the procedure. Postoperatively, a regimen of topical corticosteroids and antibiotics is introduced.

A sutureless variant for tube covering has been recently proposed. The tube is covered with human donor scleral graft and kept in place with fibrin glue (Tissue Coll $\left.{ }^{\circledR}\right) \cdot{ }^{37}$ Tissue Coll is a biologic glue with adhesive properties derived from the formation of fibrin polymers. However, costs, commercial availability, poor uniformity, and quality of donor sclera may 
limit the widespread use of this procedure. The sutureless technique has been further modified with the use of bovine pericardial graft patch (Tuttopatch, Tutogen Medical GmbH, Neunkirken am Brand, Germany) instead of human sclera, with good results in the medium term (Figure 2). ${ }^{38}$ The relative high costs of fibrin glue are in this way counterbalanced by the low cost of Tuttopatch, when compared with human scleral donor patch. The absence of sutures is advantageous in the postoperative, because sutures can promote inflammation and provide a nidus for infections or neovascularization. Written informed consent was received from the patients for this review including publication of their medical data and images.

\section{Antimetabolite and Ahmed valve surgery}

The use of antimetabolites in AGV surgery is debated. In 2004, Costa et al randomized 60 patients affected by neovacular glaucoma to receive intraoperative $\mathrm{MMC}(0.5 \mathrm{mg} / \mathrm{mL}$ for 5 minutes; $n=34)$ or BSS $(n=26)$ during surgery for AGV implantation. ${ }^{39}$ Kaplan-Meier survival analysis showed a $59 \%$ and $61 \%$ probability of success at 18 months for the MMC and control groups, respectively, with no statistically significant difference. Similar results were obtained by Kurnaz et al in a study on 48 patients affected with refractory glaucoma. ${ }^{40}$ Authors found no difference in success rates between the MMC and no-antimetabolite groups at 1 year ( $86.36 \%$ versus $80.76 \%$, respectively), but 3 cases of tube exposure were encountered in the MMC group.

Alvarado et al obtained high success rates at 6-year follow-up in patients who underwent AGV implantation (either alone or in combination with cataract surgery) with both intraoperative MMC and postoperative 5FU injections. ${ }^{41}$ MMC-soaked sponges were placed subconjuntivally for $\sim 5-8$ minutes during surgery (median: 8 minutes, MMC
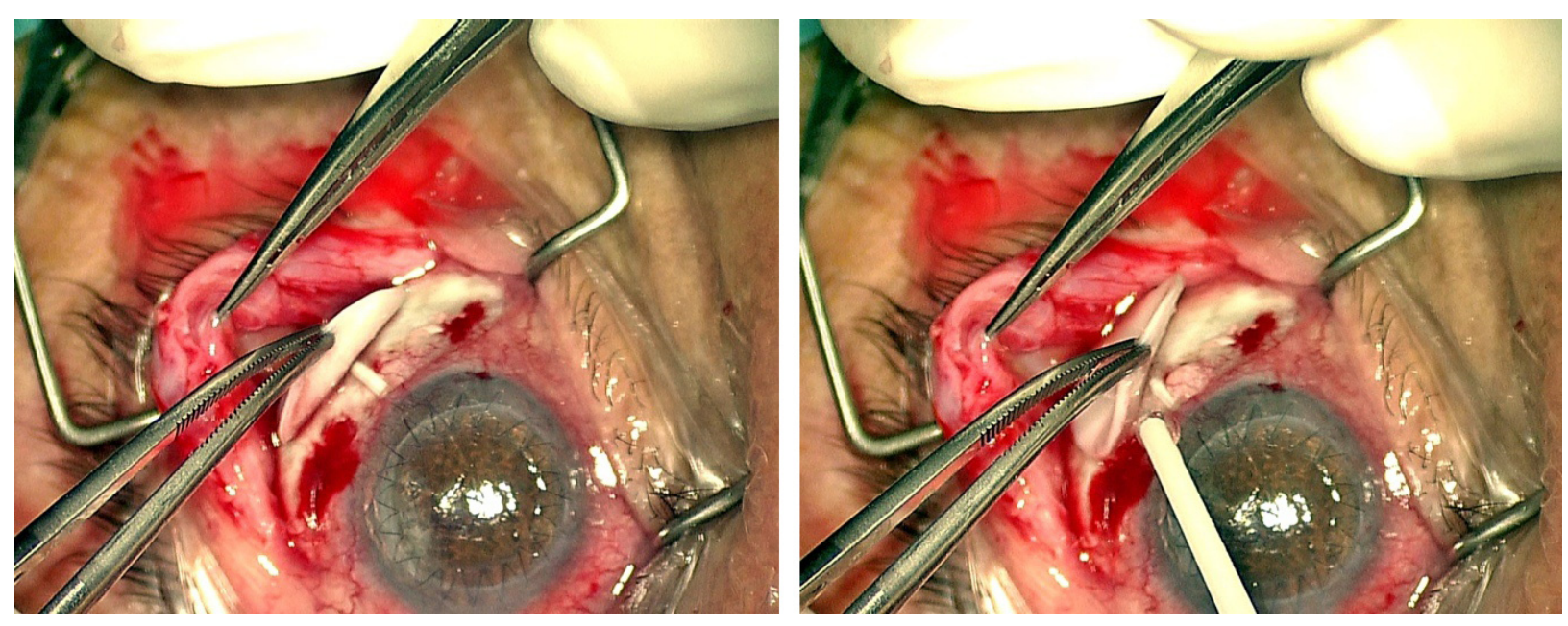

concentration: $0.5 \mathrm{mg} / \mathrm{mL}$ ). $5 \mathrm{FU}$ subconjunctival injections were performed postoperatively, for 4 consecutive weeks, starting at 1 week, with a fifth injection at week 6. Kaplan-Meier estimates of the cumulative probability of implant success at the sixth follow-up year were 0.72 and 0.84 for eyes that underwent $\mathrm{AGV}$ implantation $(\mathrm{n}=88)$ and $\mathrm{AGV}$ implantation + cataract extraction $(n=42)$, respectively. Comparing results at 2- and 4-year follow-up with those from other studies in which antimetabolites were not used, authors concluded that there was a potential benefit associated with the use of MMC and 5FU during the intraoperative and early postoperative period.

The way antimetabolites are administered could be important in determining the efficacy of the surgical procedure. Zhou et al proposed a new technique for MMC administration, in which the valve plate was first encompassed with a thin layer of cotton soaked with MMC and then positioned on the sclera. ${ }^{42}$ After 2-5 minutes, the cotton and the encompassed $\mathrm{AGV}$ were removed and irrigated with $200 \mathrm{~mL}$ BSS. In comparison with the traditional MMC administration procedure (ie, sponges soaked with MMC and applied on the sclera), the new technique obtained better results in the short and long terms. The new-technique group had only 1 case of encapsulated cyst over the plate out of 38 surgeries $(2.6 \%)$, whereas the traditional-technique group had 8 cases of encapsulated cyst out of 41 surgeries $(19.5 \%)(P=0.030)$. However, it should be noted that MMC concentrations in this study were considerably smaller than in other studies $(0.25-0.33 \mathrm{mg} / \mathrm{mL}, 2-5$ minutes $)$, and this could have biased the results.

\section{AGV complications}

A report from the American Academy of Ophthalmology has reported the major short-term (up to 5 years after surgery)

Figure 2 Ahmed glaucoma valve: sutureless implantation technique. 
to medium-term (5-10 years after surgery) complications of aqueous shunt devices. ${ }^{43}$ They include immediate and late hypotony after surgery, excessive capsule fibrosis and clinical failure, erosion of the tube or plate edge, and very rarely infection.

Actually, there is no evidence in literature about different rates of complications with $1 \mathrm{AGV}$ model than another. ${ }^{44-48}$ Although an higher IOP reduction with the silicone-plate model than the polyethylene one has been described in the short term, ${ }^{44,45,48}$ long-term results are not conclusive. ${ }^{47}$

\section{Hypotony}

AGV valve mechanism was designed with the aim of preventing postoperative hypotony, allowing for $\mathrm{AH}$ drainage when IOP is in the range of $8-12 \mathrm{mmHg}$. Studies have demonstrated that the mechanism is effective in reducing, but not abolishing, postoperative hypotony, in comparison with other nonvalve implants. ${ }^{49-55}$ The Ahmed versus Baerveldt Study (AVB Study) was a prospective, multicenter, randomized clinical trial comparing AGV (model FP7) and Baerveldt $350 \mathrm{~mm}^{2}$ implant in patients affected by refractory glaucoma. ${ }^{56}$ In this study, 7 of 114 patients (6.1\%) in the Baerveldt group experienced vision-threatening complications related to hypotony at 3-year analysis (3 developed suprachoroidal hemorrhage, 3 had retinal/choroidal detachments, and 1 had refractory hypotony), against 0 of $124 \mathrm{AGV}$ patients. $^{50}$ Similarly, in the Ahmed-Baerveldt Comparison (ABC) study, a multicenter clinical trial designed to prospectively compare safety and efficacy of these two commonly implanted devices, 1 eye $(2 \%)$ in the AGV group experienced failure due to persistent hypotony, against 6 eyes $(13 \%)$ in the Baerveldt group after 5-year follow-up. ${ }^{52}$ In comparison with Molteno implant (both single and double plates), AGV demonstrated lower risk of hypotony-related complications, both in retrospective and prospective studies. ${ }^{53-55}$ Besides these results, postoperative hypotony following the placement of $\mathrm{AGV}$ (S2 and FP7) has been reported up to $3 \%$ of cases. ${ }^{44}$

The reason of persistent hypotony after AGV implantation is not completely clear. Attention should be taken during surgical procedure to not over-prime the tube and to not excessively manipulate the valve housing, as these actions could damage the valve mechanism embedded in the implant. ${ }^{57,58}$ Importance has been placed on the utilization of a 22 or $23 \mathrm{G}$ needle when creation of the sclerostomy is undertaken in order to avoid the egress of $\mathrm{AH}$ around the silicone tube in the immediate post-operatory. ${ }^{57}$ In addition, ciliary body function may fail or decrease after surgery in complicated eyes in which glaucoma drainage implants are used..$^{59}$
In a study by Prata et al, pressure flow characteristics at physiologic flow rates, in vitro and in vivo rabbits, were evaluated for valve (Ahmed and Krupin) and nonvalve (Baerveldt and Molteno) implants. ${ }^{60}$ Authors concluded that none of the implants tested maintained advertised pressure levels during in vitro tests, when immersed and while being perfused at flow rates close to those expected in normal human eyes. $\mathrm{AGV}$ and Krupin implants functioned as flow restriction devices or regulators, rather than as valves that truly open and close in response to pressure change after immersion in fluid. In vivo, conjunctival tissue reaction surrounding the explant portion of the device contributed significantly to the outflow resistance, increasing the restriction effect due to the valve mechanism.

Besides persistent and long-term hypotony, transient hypotony in the immediate postoperatory has been frequently described after AGV implantation. An "hypotensive" phase was recorded in $13 \%$ and $15 \%$ of patients in the AVB and ABC studies, respectively. ${ }^{50,61}$ Choroidal effusion may also be present. In these cases, hypotony resolves spontaneously as soon as encapsulation of the plate increases outflow resistance, within days or weeks from the surgery. Observation should be the choice, monitoring $\mathrm{AC}$ depth and extension of choroidal detachment. Prompt intervention should be taken if shallow AC, hypotony maculopathy, or near-kissing choroidal detachment is present.

\section{IOP increase and excessive capsule fibrosis}

An "hypertensive" phase after glaucoma drainage implantation is quite common and has been frequently described in patients with AGV. Typically, this phase peaks at 1 or 2 months postoperatively and resolves within 6 months. ${ }^{31,62-64}$ The hypertensive phase could be less frequent in patients who have been implanted with the silicone than with the polypropylene AGV, probably because silicone is less inflammatory than polypropylene. ${ }^{44}$ The primary reason for elevated IOP in the postoperative period is from capsular fibrosis. Attempts have been made to modulate the fibrotic reaction around the plate, varying plate size, shape, flexibility, and materials. ${ }^{26}$ Initial data showed that a mitigation of the early postoperative hypertensive phase may be achievable with the new M4 AGV model, in comparison with the FP7 and S2 model. ${ }^{32}$

An option in the management of the hypertensive phase is, similar to trabeculectomy, digital massage. ${ }^{65,66}$ The purpose of digital massage is to force $\mathrm{AH}$ through the tube, opening the valve mechanism, and reducing scar formation. Caution should be placed in this maneuver in order to avoid repeated tube-corneal endothelial touch. 
Late IOP increase ( $>6$ months) is the main cause of longterm failure of AGV surgery. If encapsulation of the plate is evident, a needling revision of the bleb may be attempted, with the aim of reducing outflow resistance. An encapsulated bleb is recognizable as a bleb that has been walled-off by the Tenon's capsule, resulting in a rigid elevation of the mobile conjunctival tissue. Quaranta et al performed bleb needling with 5FU at the slit lamp in 36 consecutive patients implanted with an S2 AGV, noncontrolled IOP, and encapsulated bleb over the plate. ${ }^{67}$ Qualified success (IOP $\leq 18 \mathrm{mmHg}$ with or without medications) was achieved at $1,3,6,12,18$, and 24 months in $100 \%, 97.8 \%, 86.1 \%, 75 \%, 75 \%$, and $72.2 \%$, respectively. Complications were encountered in 14 eyes (38.8\%) and resolved spontaneously in 12 out of 14 cases.

If medical therapy and needling revision are not successful, surgical revision of the implant should be performed. Conjunctiva is dissected over the encapsulated bleb, and the cyst wall is excised. After excision, the conjunctiva is closed with a nylon or vicryl suture. In a retrospective study by Eibschitz-Tsimhoni et al, surgical revision was effective in achieving adequate IOP control in 8 of 11 patients, with or without medications. ${ }^{68}$ However, in 3 patients, cyst excision was not successful, and further surgical interventions were needed.

\section{Tube exposure}

Tube exposure is a well-known complication of glaucoma drainage implants (Figure 3). Erosion of the conjunctiva and of the covering patch graft has been described in the late postoperative period in $2 \%-7 \%$ of eyes after implantation of glaucoma devices..$^{62,69-74} \mathrm{With}$ regard to $\mathrm{AGV}$, frequency of tube exposure varies from $5 \%$ to $14.3 \%$ of cases. ${ }^{63,75,76}$ In a recently published study on 12 patients, tube exposure has been encountered in up to $30.8 \%$ of cases ${ }^{77}$ However, these high frequencies are not in accordance with data deriving from multicenter studies.

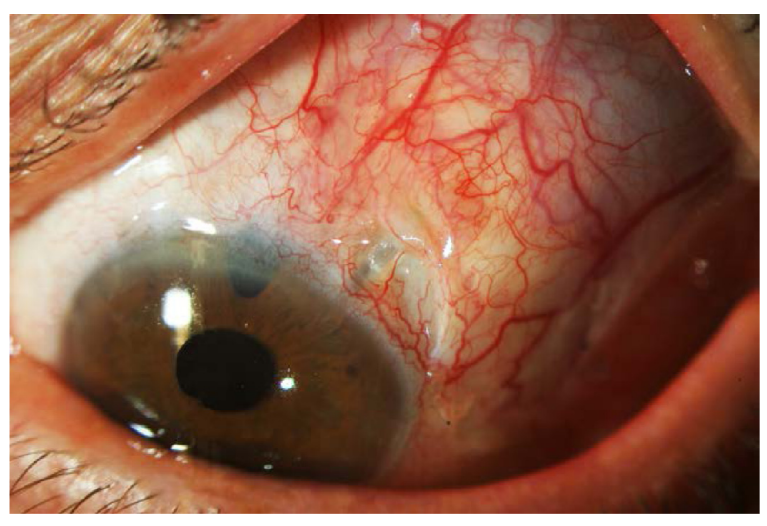

Figure 3 Ahmed glaucoma valve: tube exposure due to conjunctival erosion.
Tube exposure can lead to ocular inflammation, hypotony, poor vision, and phthisis. Most of all, tube exposure represents a major risk factor for the development of late endophthalmitis, as the exposed tube provides a way for microorganisms to migrate into the eye from ocular surface and conjunctiva. ${ }^{78,79}$ Although covering the tube with a patch graft material has markedly reduced the rate of tube exposure, ${ }^{80}$ no significant difference in patch graft survival has been found when sclera, dura, and pericardium were compared. ${ }^{73}$

The mechanism responsible for tube exposure is not completely clear. A high grade, immune-mediated process could be responsible for rapid melting ( $<6$ months) of the patch, via cell- or noncell immune-mediated process. ${ }^{73}$ A mechanical process could be involved in patch erosion as well. If tube is not fixed on the sclera, continuous and minimum movements may produce tube-graft tension, resulting in gradual patch atrophy. ${ }^{73,81}$ Finally, patch melting could occur as a result of a low grade, possibly immune-mediated, long-term, atrophy process, with consequent gradual patch thinning. ${ }^{73}$

Chaku et al evaluated risk factors for tube exposure in a comparative, retrospective study of 64 eyes, including 32 eyes with tube exposure and 32 control eyes.$^{81}$ All patients had a glaucoma drainage device implanted, including $35 \mathrm{AGVs}$ and 29 Baerveldt implants. Patients developed tube exposure at a mean of $1.43 \pm 1.5$ years from surgery, and no difference was found in the rate of exposure between AGV and Baerveldt implant. In both univariate and multivariate analyses, younger age $(P<0.01$ and $P=0.02)$ and inflammation prior to tube exposure $(P<0.01)$ were significant risk factors for tube exposure. Diabetes was a significant factor only in the univariate analysis $(P=0.02)$.

In a meta-analysis by Stewart et al, 38 previously published studies describing conjunctival erosion in patients with a glaucoma device (16 AGVs, 12 Baerveldt, and 17 Molteno implants) were evaluated. ${ }^{82}$ A total of 3,105 patients and 3,255 eyes with an average follow-up of $26.1 \pm 3.3$ months were included in the analysis. The incidence of tube exposure from these studies was $2.0 \% \pm 2.6 \%(n=64)$, with an average exposure rate per month of $0.09 \% \pm 0.14 \%$. No difference was found among AGV, Baerveldt, and Molteno implant. Although the correlation between study length and incidence of exposure was not significant, there appeared to be a little increase in exposure incidence for studies up to 2-year follow-up.

Implant positioning may be important in determining the risk of tube exposure. In a study by Pakravan et al, 58 eyes underwent AGV implantation in the superotemporal 
quadrant and 48 eyes in the inferior quadrants. ${ }^{83}$ Although no difference was found between the 2 groups in terms of IOP reduction, the inferior implant group had a higher rate of complications $(P<0.01)$. One eye $(1.7 \%)$ in the superior group and 4 eyes (8.3\%) in the inferior group required AGV explantation because of conjunctival erosion and implant exposure, unresponsive to conservative measures and surgical intervention $(P=0.173)$. Other studies, comprising different models of glaucoma implants than AGV, confirmed that the location of the implant may be important to prevent tube exposure. ${ }^{84,85}$

In a report by the American Academy of Ophthalmology, authors suggest that the observation of the loss of conjunctival capillaries over the tube, usually $1-3 \mathrm{~mm}$ from the corneoscleral junction, is an indication of impending erosion through the surface ${ }^{43}$ Before exposure of the tube, repatching can be accomplished in these cases by redissection from the posterior aspect of the patch and placement of a new patch, ideally donor-preserved sclera, under intact conjunctiva. If exposure of the tube is already present, surgical repairing may be more difficult. Extensive lateral dissection of the conjunctiva should be performed to obtain sufficient mobility to recover the implant. However, in eyes with previous multiple surgeries, covering the new patch with conjunctiva may be difficult, due to the fragile nature of the tissue and firm adhesion of the conjunctiva to underlying scar tissue. In these cases, many solutions have been undertaken, such as the use of buccal membrane, ${ }^{86}$ amniotic membrane, ${ }^{87}$ or autologous conjunctiva ${ }^{88}$ As a general rule, as long as the edges of the patch graft are covered by conjunctiva, healing usually occurs by migrating conjunctival epithelium over the central defect.

\section{Corneal complications}

The presence of the silicone tube in the $\mathrm{AC}$ is known to disturb corneal endothelium and may induce corneal decompensation and edema. ${ }^{89}$ The exact frequency of corneal issues in patients implanted with AGV is not known, but it has been reported to be $9 \%-27 \%$ in the long term. ${ }^{89-91}$

Topouzis et al, after a mean follow-up of 30.5 months, found a $27 \%$ incidence of corneal decompensation in patients who underwent AGV implantation. ${ }^{91}$ However, in this study, 16 of the 60 eyes enrolled had prior or concurrent corneal grafts and 9 of these 16 eyes had corneal graft failure during the follow-up. In the ABC study, persistent corneal edema was recorded in $20.1 \%$ of patients in the AGV group, at 5 years from surgery. ${ }^{51}$ However, edema was attributed to nonimplant causes in $50 \%$ of cases, so that the real percentage of subjects with persistent corneal edema due to the implant was $12 \%$. No difference was found between AGV and Baerveldt implant in terms of persistent corneal edema incidence (20.1\% and $20.4 \%$, respectively). In the AVB study, corneal edema affected $7 \%$ of patients in the AGV group and $14 \%$ of patients in the Baerveldt group at 3-year follow-up $(P=0.08) .{ }^{50}$ Authors hypothesized that the higher rate of corneal edema in the Baerveldt group was the result of greater IOP variability in the early postoperative phase.

The exact mechanism causing endothelial damage in patients with a drainage implant is unknown. Jet flow around the end of the tube caused by heartbeat, AC inflammation, intermittent tube-corneal touch, tube-uveal touch, and foreign body reaction to the silicon tube are all potential mechanisms of endothelial damage in these patients. ${ }^{92}$ However, factors independent of tube existence in the $\mathrm{AC}$ may contribute to corneal decompensation. High IOP and long duration of elevated IOP before surgery, toxicity of eye-drop preservatives, duration of surgery, and changes in the composition of AH may influence endothelial cell functions and take a part in corneal decompensation. ${ }^{93,94}$

Endothelial cell loss in patients implanted with AGV has been prospectively and retrospectively evaluated. Kim et al found a mean percentage decrease in corneal endothelial cell density of $3.5 \%$ at 1 month, $7.6 \%$ at 6 months, and $10.5 \%$ at 12 months from surgery. ${ }^{95}$ Lee et al recorded an average decrease in corneal endothelial cell count of $5.8 \%$ at 1 month, $11.5 \%$ at 6 months, $15.3 \%$ at 12 months, $16.6 \%$ at 18 months, and $18.6 \%$ at 24 months from surgery. ${ }^{96}$ In both studies, the superotemporal area, which was closest to the site of the tube, showed the greatest decrease in endothelial cell count, whereas the central area showed the smallest decrease. Besides these data, in the study by Lee et al, Kaplan-Meier analysis showed an alarming $36.6 \%$ cumulative rate of failure (ie, patients with a decrease in central corneal endothelial cell density $>20 \%$ ) at 24 months. ${ }^{96}$

In a recent study, medical records of 127 patients who underwent $\mathrm{AGV}$ implantation were retrospectively reviewed to evaluate changes in corneal endothelial cell density and rates of corneal decompensation..$^{97}$ Mean follow-up was $43.1 \pm 20.5$ months, with $53 \%$ of patients followed-up to 60 months. Corneal decompensation occurred only in 3 cases and the cumulative risk of corneal decompensation was $3.3 \%$ at 5 years from surgery. Seventy-two eyes were evaluated for annual change in endothelial cell count and compared with 31 control eyes. Although a more rapid loss of endothelial cell count was found in these 72 eyes compared with controls $(-7.0 \%$ and $-0.1 \%$ / year, respectively; $P<0.01$ ), the rate of loss decreased over 
time and statistical significance compared with control eyes disappeared after 2 years postoperatively.

Apart from corneal decompensation due to direct tubecorneal touch, tube position could be important in determining corneal complications. Koo et al measured various $\mathrm{AH}$ parameters in 39 eyes with previous superotemporal AGV implantation. ${ }^{98}$ Parameters measured included tube distance from the cornea, tube angle, and AC tube length. All parameters were obtained by anterior segment optical coherent tomography. In univariate analysis, tube-cornea angle and the closest distance from the tip of the tube to the cornea were statistically significant predictors of superotemporal corneal endothelial cell loss after glaucoma surgery. In multivariate analysis, only the distance from the tip of the tube to the cornea was significant; each millimeter that the tube was closer to the endothelial surface was associated with 353.1 (95\% CI, 56.1-650.1; $P=0.02$ ) fewer endothelial cells.

In patients with corneal decompensation and AGV, Descemet stripping endothelial keratoplasty (DSAEK) has been attempted, with survival rates at 1 year similar to full-thickness keratoplasty. ${ }^{99}$ Surgical procedure can be challenging in these cases. The length and location of the glaucoma drainage tube within the AC may need to be modified for DSAEK to be successful, and eventually the glaucoma implant posteriorly repositioned. ${ }^{100,101}$ Moreover, air management is often difficult because injected air may escape through the implant to the subconjunctival space, thereby making it difficult to obtain a firm intraoperative fill. ${ }^{100-102}$ This is consistent with a potential high rate of early postoperative graft detachment. ${ }^{99,101}$ Finally, a higher rate of endothelial cell loss has been described in eyes with AGV and previous DSAEK, compared with nonglaucomatous eyes. In a study by Kim et al, mean reduction in graft endothelial cell count was $69 \%$ over a 20 -month follow-up period, ${ }^{101}$ whereas Schoenberg et al found an average endothelial cell loss of $40.7 \%$ at 12 months from surgery. ${ }^{99}$

\section{Infection and endophthalmitis}

Endophthalmitis or infections associated with grafting material covering the tube is a rare complication of glaucoma drainage implants. For this reason, recurrent blebitis after trabeculectomy can be a reasonable indication for shunt implantation, according to a report by the American Academy of Ophthalmology. ${ }^{43}$ Several retrospective studies about glaucoma drainage implants included few cases of endophthalmitis, resulting in rates ranging from $0.8 \%$ to $6.3 \%$ (mean: $2.0 \%$ ). ${ }^{78}$ There appears to be no significant difference in reported rates of endophthalmitis among various glaucoma drainage implants. ${ }^{78,103}$
In a retrospective study, Al-Torbak et al reviewed records of patients implanted with AGV from 1994 to 2003 in a single eye hospital in Saudi Arabia and found an incidence of endophthalmitis of $1.7 \%$ (9 patients on 542 implanted). ${ }^{78}$ Five cases of endophthalmitis were detected in pediatric patients (ie, age $<18$ years) and 4 in adults. Median interval between AGV implantation and diagnosis of endophthalmitis was 260 days and delayed onset endophthalmitis developed in 8 of 9 eyes ( $88.8 \%$ ). Conjunctival erosion over the tube was found in 6 of 9 patients $(66.6 \%)$ who developed endophthalmitis and 4 of 6 eyes (66.6\%) had a Seidel-positive leak. Multiple regression analysis revealed younger age $(<18$ years; $P<0.05)$ and conjunctival erosion over the tube $(P<0.01)$ as significant risk factors for endophthalmitis development.

Conjunctival erosion and tube exposure appear to be a major risk factor for infection development in eyes with glaucoma drainage implants. Several case reports in literature describe episodes of late endophthalmitis in patients with AGV and tube exposure. ${ }^{104-107}$ It has been postulated that the exposed tube may act as a direct channel for the intraocular passage of the conjunctival flora from the ocular surface. ${ }^{103}$ Younger age is another major risk factor. Case series of pediatric patients implanted with glaucoma drainage devices have shown an incidence of endophthalmitis ranging from $2.9 \%$ to $5 \%$. ${ }^{103,108,109}$ This could be related to the higher rate of conjunctival erosion and implant exposure in children. ${ }^{109,110}$ Interestingly, younger age has been advocated as a significant risk factor for endophthalmitis also in patients who underwent trabeculectomy, with an incidence of late bleb-related endophthalmitis as high as $8.3 \%$ in the pediatric population. ${ }^{103}$

\section{Diplopia and strabismus}

Diplopia and strabismus are well-known postsurgical complications of glaucoma drainage devices. ${ }^{43}$ The cause of diplopia is likely a restrictive strabismus, either from the plate itself or from the plate impinging on the muscle insertion. ${ }^{111}$ Manipulation of the rectus muscles during surgery may induce strabismus as well, which usually resolves spontaneously in weeks or months. ${ }^{63}$ A systematic review of literature by Hong et al found an higher incidence of diplopia in patients with Baerveldt implant compared with patients with other glaucoma devices. ${ }^{111}$ However, the ABC study found an equal, $\sim 12 \%$ cumulative risk of persistent diplopia in both the AGV and Baerveldt groups. ${ }^{52}$ Authors suggested that the end-plate fenestrations of the new designed Baerveldt implant (applied in the ABC study) could reduce the height of the bleb and consequently minimize restrictive strabismus. For this reason, an equal risk of diplopia may have been found in both groups of the ABC study. 
In a retrospective study, including 159 eyes implanted with AGV, Huang et al found diplopia in 4 patients $(2.5 \%)$, 3 requiring extraocular muscle surgery and 1 who had removal of the device. ${ }^{62}$ However, Ayyala et al reported an incidence of transient diplopia of 4.7\% (4 of 85) in patients who underwent AGV surgery. ${ }^{63}$ Fifty percent cases of diplopia occurred within 3 months of surgery.

\section{Conclusion}

AGV implantation is an effective and relatively safe surgical procedure, which allows to manage particular phenotypes of glaucoma (ie, secondary glaucoma) and glaucoma refractory to previous filtration surgeries (ie, second choice surgery). Despite an apparently "user-friendly" technique, many surgical tips are to be acquired by the surgeon, and a long learning curve is always needed. In comparison with other nonvalve glaucoma drainage devices, AGV has the great advantage of an easier postoperative management. Nevertheless, early postoperative hypotony is still a dangerous complication that can affect this type of surgery.

\section{Acknowledgment}

The contribution of the IRCCS Fondazione GB Bietti per l'Oftalmologia in this paper was supported by Ministry of Health and Fondazione Roma.

\section{Disclosure}

The authors report no conflicts of interest in this work.

\section{References}

1. Tham YC, Li X, Wong TY, Quigley HA, Aung T, Cheng CY. Global prevalence of glaucoma and projections of glaucoma burden through 2040: a systematic review and meta-analysis. Ophthalmology. 2014; 121(11):2081-2090

2. Leske MC, Heijl A, Hussein M, Bengtsson B, Hyman L, Komaroff E; Early Manifest Glaucoma Trial Group. Factors for glaucoma progression and the effect of treatment: the early manifest glaucoma trial. Arch Ophthalmol. 2003;121(1):48-56.

3. Gordon MO, Beiser JA, Brandt JD, et al. The ocular hypertension treatment study: baseline factors that predict the onset of primary open-angle glaucoma. Arch Ophthalmol. 2002;120(6):714-720.

4. Gordon MO, Torri V, Miglior S, et al; Ocular Hypertension Treatment Study G, European Glaucoma Prevention Study. Validated prediction model for the development of primary open-angle glaucoma in individuals with ocular hypertension. Ophthalmology. 2007;114(1):10-19.

5. Nouri-Mahdavi K, Hoffman D, Coleman AL, et al. Predictive factors for glaucomatous visual field progression in the advanced glaucoma intervention study. Ophthalmology. 2004;111(9):1627-1635.

6. Green CM, Kearns LS, Wu J, et al; Advanced Glaucoma Intervention Study. How significant is a family history of glaucoma? Experience from the glaucoma inheritance study in Tasmania. Clin Exp Ophthalmol. 2007;35(9):793-799.

7. Pillunat LE, Stodtmeister R, Marquardt R, Mattern A. Ocular perfusion pressures in different types of glaucoma. Int Ophthalmol. 1989;13(1-2): $37-42$.
8. Quaranta L, Manni G, Donato F, Bucci MG. The effect of increased intraocular pressure on pulsatile ocular blood flow in low tension glaucoma. Surv Ophthalmol. 1994;(Suppl 38):S177-S181.

9. Quaranta L, Katsanos A, Russo A, Riva I. 24-hour intraocular pressure and ocular perfusion pressure in glaucoma. Surv Ophthalmol. 2013; 58(1):26-41.

10. Garway-Heath DF, Crabb DP, Bunce C, et al. Latanoprost for open-angle glaucoma (UKGTS): a randomised, multicentre, placebocontrolled trial. Lancet. 2015;385(9975):1295-1304.

11. Rulli E, Biagioli E, Riva I, et al. Efficacy and safety of trabeculectomy vs nonpenetrating surgical procedures: a systematic review and metaanalysis. JAMA Ophthalmol. 2013;131(12):1573-1582.

12. Prum BE Jr, Rosenberg LF, Gedde SJ, et al. Primary Open-Angle Glaucoma Preferred Practice Pattern((R)) Guidelines. Ophthalmology. 2016;123(1):P41-P111.

13. Cairns JE. Trabeculectomy. Preliminary report of a new method. Am J Ophthalmol. 1968;66(4):673-679.

14. Law SK, Shih K, Tran DH, Coleman AL, Caprioli J. Long-term outcomes of repeat vs initial trabeculectomy in open-angle glaucoma. Am J Ophthalmol. 2009;148(5):685-695. e681.

15. Edmunds B, Thompson JR, Salmon JF, Wormald RP. The National Survey of Trabeculectomy. II. Variations in operative technique and outcome. Eye (Lond). 2001;15(Pt 4):441-448.

16. Scott IU, Greenfield DS, Schiffman J, et al. Outcomes of primary trabeculectomy with the use of adjunctive mitomycin. Arch Ophthalmol. 1998;116(3):286-291.

17. Wilensky JT, Chen TC. Long-term results of trabeculectomy in eyes that were initially successful. Trans Am Ophthalmol Soc. 1996;94: $147-159$.

18. Molteno AC, Bosma NJ, Kittelson JM. Otago glaucoma surgery outcome study: long-term results of trabeculectomy - 1976 to 1995. Ophthalmology. 1999;106(9):1742-1750.

19. Bevin TH, Molteno AC, Herbison P. Otago Glaucoma Surgery Outcome Study: long-term results of 841 trabeculectomies. Clin Exp Ophthalmol. 2008;36(8):731-737.

20. Landers J, Martin K, Sarkies N, Bourne R, Watson P. A twenty-year followup study of trabeculectomy: risk factors and outcomes. Ophthalmology. 2012;119(4):694-702.

21. Takihara $\mathrm{Y}$, Inatani $\mathrm{M}$, Fukushima $\mathrm{M}$, Iwao K, Iwao M, Tanihara $\mathrm{H}$ Trabeculectomy with mitomycin $\mathrm{C}$ for neovascular glaucoma: prognostic factors for surgical failure. Am J Ophthalmol. 2009;147(5):912-918.

22. Iwao K, Inatani M, Seto T, et al. Long-term outcomes and prognostic factors for trabeculectomy with mitomycin $\mathrm{C}$ in eyes with uveitic glaucoma: a retrospective cohort study. J Glaucoma. 2014;23(2):88-94.

23. Bettis DI, Morshedi RG, Chaya C, Goldsmith J, Crandall A, Zabriskie N. Trabeculectomy with mitomycin $\mathrm{C}$ or Ahmed valve implantation in eyes with uveitic glaucoma. J Glaucoma. 2015;24(8):591-599.

24. Singh D, Chandra A, Sihota R, Kumar S, Gupta V. Long-term success of mitomycin-augmented trabeculectomy for glaucoma after vitreoretinal surgery with silicone oil insertion: a prospective case series. Retina. 2014; 34(1):123-128.

25. Gedde SJ, Schiffman JC, Feuer WJ, Herndon LW, Brandt JD, Budenz DL; Tube versus Trabeculectomy Study Group. Treatment outcomes in the tube versus trabeculectomy (TVT) study after five years of follow-up. Am J Ophthalmol. 2012;153(5):789-803.

26. Patel S, Pasquale LR. Glaucoma drainage devices: a review of the past, present, and future. Semin Ophthalmol. 2010;25(5-6):265-270.

27. Rollet M. Le drainage au irin de la chambre anterieure contre l'hypertonie et al douleur. Rev Gen Ophthalmol. 1906;25:481.

28. Molteno AC, Straughan JL, Ancker E. Long tube implants in the management of glaucoma. S Afr Med J. 1976;50(27):1062-1066.

29. Krupin T, Podos SM, Becker B, Newkirk JB. Valve implants in filtering surgery. Am J Ophthalmol. 1976;81(2):232-235.

30. Krupin eye valve with disk for filtration surgery. The Krupin Eye Valve Filtering Surgery Study Group. Ophthalmology. 1994;101(4):651-658.

31. Coleman AL, Hill R, Wilson MR, et al. Initial clinical experience with the Ahmed glaucoma valve implant. Am J Ophthalmol. 1995;120(1): $23-31$. 
32. Kim J, Allingham RR, Hall J, Klitzman B, Stinnett S, Asrani S. Clinical experience with a novel glaucoma drainage implant. J Glaucoma. 2014; 23(2):e91-e97.

33. Klawitter JJ, Bagwell JG, Weinstein AM, Sauer BW. An evaluation of bone growth into porous high density polyethylene. J Biomed Mater Res. 1976;10(2):311-323.

34. Spector M, Harmon SL, Kreutner A. Characteristics of tissue growth into proplast and porous polyethylene implants in bone. J Biomed Mater Res. 1979;13(5):677-692.

35. DeCroos FC, Kondo Y, Mordes D, et al. In vitro fluid dynamics of the Ahmed glaucoma valve modified with expanded polytetrafluoroethylene. Curr Eye Res. 2011;36(2):112-117.

36. Pandav S, Banger A, Ichpujani P, Raj S, Kaushik S. Results of Ahmed glaucoma valve implantation with "hangback" technique. World Glaucoma Congress; 2011; Paris.

37. Zeppa L, Romano MR, Capasso L, Tortori A, Majorana MA, Costagliola C. Sutureless human sclera donor patch graft for Ahmed glaucoma valve. Eur J Ophthalmol. 2010;20(3):546-551.

38. Quaranta L, Riva I, Floriani IC. Outcomes of using a sutureless bovine pericardial patch graft for Ahmed glaucoma valve implantation. Eur J Ophthalmol. 2013;23(5):738-742.

39. Costa VP, Azuara-Blanco A, Netland PA, Lesk MR, Arcieri ES. Efficacy and safety of adjunctive mitomycin $\mathrm{C}$ during Ahmed glaucoma valve implantation: a prospective randomized clinical trial. Ophthalmology. 2004;11(6):1071-1076.

40. Kurnaz E, Kubaloglu A, Yilmaz Y, Koytak A, Ozerturk Y. The effect of adjunctive mitomycin $\mathrm{C}$ in Ahmed glaucoma valve implantation. Eur J Ophthalmol. 2005;15(1):27-31.

41. Alvarado JA, Hollander DA, Juster RP, Lee LC. Ahmed valve implantation with adjunctive mitomycin $\mathrm{C}$ and 5-fluorouracil: long-term outcomes. Am J Ophthalmol. 2008;146(2):276-284.

42. Zhou M, Wang W, Huang W, Zhang X. Use of mitomycin C to reduce the incidence of encapsulated cysts following Ahmed glaucoma valve implantation in refractory glaucoma patients: a new technique. $B M C$ Ophthalmol. 2014;14:107.

43. Minckler DS, Francis BA, Hodapp EA, et al. Aqueous shunts in glaucoma: a report by the American Academy of Ophthalmology. Ophthalmology. 2008;115(6):1089-1098.

44. Ishida K, Netland PA, Costa VP, Shiroma L, Khan B, Ahmed II. Comparison of polypropylene and silicone Ahmed glaucoma valves. Ophthalmology. 2006;113(8):1320-1326.

45. Law SK, Nguyen A, Coleman AL, Caprioli J. Comparison of safety and efficacy between silicone and polypropylene Ahmed glaucoma valves in refractory glaucoma. Ophthalmology. 2005;112(9):1514-1520.

46. Brasil MV, Rockwood EJ, Smith SD. Comparison of silicone and polypropylene Ahmed glaucoma valve implants. J Glaucoma. 2007; 16(1):36-41.

47. Mackenzie PJ, Schertzer RM, Isbister CM. Comparison of silicone and polypropylene Ahmed glaucoma valves: two-year follow-up. Can J Ophthalmol. 2007;42(2):227-232.

48. Hinkle DM, Zurakowski D, Ayyala RS. A comparison of the polypropylene plate Ahmed glaucoma valve to the silicone plate Ahmed glaucoma flexible valve. Eur J Ophthalmol. 2007;17(5):696-701.

49. Christakis PG, Kalenak JW, Zurakowski D, et al. The Ahmed versus Baerveldt study: one-year treatment outcomes. Ophthalmology. 2011; 118(11):2180-2189.

50. Christakis PG, Tsai JC, Kalenak JW, et al. The Ahmed versus Baerveldt study: three-year treatment outcomes. Ophthalmology. 2013;120(11): 2232-2240

51. Budenz DL, Barton K, Gedde SJ, et al; Ahmed Baerveldt Comparison Study Group. Five-year treatment outcomes in the Ahmed Baerveldt comparison study. Ophthalmology. 2015;122(2):308-316.

52. Budenz DL, Feuer WJ, Barton K, et al; Ahmed Baerveldt Comparison Study Group. Postoperative complications in the Ahmed Baerveldt comparison study during five years of follow-up. Am J Ophthalmol. 2016;163:75.e73-82.e73.
53. Ayyala RS, Zurakowski D, Monshizadeh R, et al. Comparison of doubleplate Molteno and Ahmed glaucoma valve in patients with advanced uncontrolled glaucoma. Ophthalmic Surg Lasers. 2002;33(2):94-101.

54. Nassiri N, Kamali G, Rahnavardi M, et al. Ahmed glaucoma valve and single-plate Molteno implants in treatment of refractory glaucoma: a comparative study. Am J Ophthalmol. 2010;149(6):893-902.

55. Taglia DP, Perkins TW, Gangnon R, Heatley GA, Kaufman PL. Comparison of the Ahmed glaucoma valve, the Krupin eye valve with disk, and the double-plate molteno implant. J Glaucoma. 2002; 11(4):347-353.

56. Christakis PG, Tsai JC, Zurakowski D, Kalenak JW, Cantor LB, Ahmed II. The Ahmed Versus Baerveldt study: design, baseline patient characteristics, and intraoperative complications. Ophthalmology. 2011; 118(11):2172-2179.

57. Bailey AK, Sarkisian SR Jr. Complications of tube implants and their management. Curr Opin Ophthalmol. 2014;25(2):148-153.

58. Sarkisian SR Jr. Tube shunt complications and their prevention. Curr Opin Ophthalmol. 2009;20(2):126-130.

59. Krupin T, Ritch R, Camras CB, et al. A long Krupin-Denver valve implant attached to a 180 degrees scleral explant for glaucoma surgery. Ophthalmology. 1988;95(9):1174-1180.

60. Prata JA Jr, Mermoud A, LaBree L, Minckler DS. In vitro and in vivo flow characteristics of glaucoma drainage implants. Ophthalmology. 1995; 102(6):894-904.

61. Budenz DL, Barton K, Feuer WJ, et al; Ahmed Baerveldt Comparison Study Group. Treatment outcomes in the Ahmed Baerveldt Comparison Study after 1 year of follow-up. Ophthalmology. 2011;118(3):443-452.

62. Huang MC, Netland PA, Coleman AL, Siegner SW, Moster MR, Hill RA. Intermediate-term clinical experience with the Ahmed glaucoma valve implant. Am J Ophthalmol. 1999;127(1):27-33.

63. Ayyala RS, Zurakowski D, Smith JA, et al. A clinical study of the Ahmed glaucoma valve implant in advanced glaucoma. Ophthalmology. 1998;105(10):1968-1976.

64. Nouri-Mahdavi K, Caprioli J. Evaluation of the hypertensive phase after insertion of the Ahmed glaucoma valve. Am J Ophthalmol.2003;136(6): 1001-1008.

65. McIlraith I, Buys Y, Campbell RJ, Trope GE. Ocular massage for intraocular pressure control after Ahmed valve insertion. Can J Ophthalmol. 2008;43(1):48-52.

66. Smith M, Geffen N, Alasbali T, Buys YM, Trope GE. Digital ocular massage for hypertensive phase after Ahmed valve surgery. J Glaucoma. 2010;19(1):11-14.

67. Quaranta L, Floriani I, Hollander L, Poli D, Katsanos A, Konstas AG. Needle revision with 5-fluorouracil for the treatment of Ahmed glaucoma valve filtering blebs: 5 -fluoruracil needling revision can be a useful and safe tool in the management of failing Ahmed glaucoma valve filtering blebs. J Glaucoma. 2016;25(4):e367-e371.

68. Eibschitz-Tsimhoni M, Schertzer RM, Musch DC, Moroi SE. Incidence and management of encapsulated cysts following Ahmed glaucoma valve insertion. J Glaucoma. 2005;14(4):276-279.

69. Byun YS, Lee NY, Park CK. Risk factors of implant exposure outside the conjunctiva after Ahmed glaucoma valve implantation. Jpn J Ophthalmol. 2009;53(2):114-119.

70. Wishart PK, Choudhary A, Wong D. Ahmed glaucoma valves in refractory glaucoma: a 7-year audit. Br J Ophthalmol. 2010;94(9):1174-1179.

71. Mills RP, Reynolds A, Emond MJ, Barlow WE, Leen MM. Long-term survival of Molteno glaucoma drainage devices. Ophthalmology. 1996; 103(2):299-305.

72. Vuori ML. Molteno aqueous shunt as a primary surgical intervention for uveitic glaucoma: long-term results. Acta Ophthalmol. 2010; 88(1):33-36.

73. Smith MF, Doyle JW, Ticrney JW Jr. A comparison of glaucoma drainage implant tube coverage. J Glaucoma. 2002;11(2):143-147.

74. Siegner SW, Netland PA, Urban RC Jr, et al. Clinical experience with the Baerveldt glaucoma drainage implant. Ophthalmology. 1995; 102(9):1298-1307. 
75. Montanez FJ, Laso E, Suner M, Amaya C. [Ahmed drainage device implant. Our experience between 1995 and 2003]. Arch Soc Esp Oftalmol. 2005;80(4):239-244.

76. Chen H, Zhang SX, Liu L, et al. [Intermediate-term and long-term clinical evaluation of the Ahmed glaucoma valve implantation]. Zhonghua Yan Ke Za Zhi. 2005;41(9):796-802. Chinese.

77. Kaya M, Ozbek Z, Yaman A, Durak I. Long-term success of ahmed glaucoma valve in refractory glaucoma. Int J Ophthalmol. 2012;5(1): $108-112$.

78. Al-Torbak AA, Al-Shahwan S, Al-Jadaan I, Al-Hommadi A, Edward DP. Endophthalmitis associated with the Ahmed glaucoma valve implant. Br J Ophthalmol. 2005;89(4):454-458.

79. Gedde SJ, Scott IU, Tabandeh H, et al. Late endophthalmitis associated with glaucoma drainage implants. Ophthalmology. 2001;108(7):1323-1327.

80. Heuer DK, Budenz D, Coleman A. Aqueous shunt tube erosion. J Glaucoma. 2001;10(6):493-496.

81. Chaku M, Netland PA, Ishida K, Rhee DJ. Risk factors for tube exposure as a late complication of glaucoma drainage implant surgery. Clin Ophthalmol. 2016;10:547-553.

82. Stewart WC, Kristoffersen CJ, Demos CM, Fsadni MG, Stewart JA. Incidence of conjunctival exposure following drainage device implantation in patients with glaucoma. Eur J Ophthalmol. 2010;20(1):124-130.

83. Pakravan M, Yazdani S, Shahabi C, Yaseri M. Superior versus inferior Ahmed glaucoma valve implantation. Ophthalmology. 2009;116(2): 208-213.

84. Levinson JD, Giangiacomo AL, Beck AD, et al. Glaucoma drainage devices: risk of exposure and infection. Am J Ophthalmol. 2015;160(3): 516-521.

85. Trubnik V, Zangalli C, Moster MR, et al. Evaluation of risk factors for glaucoma drainage device-related erosions: a retrospective case-control study. J Glaucoma. 2015;24(7):498-502.

86. Low SA, Rootman DB, Rootman DS, Trope GE. Repair of eroded glaucoma drainage devices: mid-term outcomes. J Glaucoma. 2012; 21(9):619-622.

87. Ainsworth G, Rotchford A, Dua HS, King AJ. A novel use of amniotic membrane in the management of tube exposure following glaucoma tube shunt surgery. Br J Ophthalmol. 2006;90(4):417-419.

88. Godfrey DG, Merritt JH, Fellman RL, Starita RJ. Interpolated conjunctival pedicle flaps for the treatment of exposed glaucoma drainage devices. Arch Ophthalmol. 2003;121(12):1772-1775.

89. Wilson MR, Mendis U, Paliwal A, Haynatzka V. Long-term follow-up of primary glaucoma surgery with Ahmed glaucoma valve implant versus trabeculectomy. Am J Ophthalmol. 2003;136(3):464-470.

90. Kook MS, Yoon J, Kim J, Lee MS. Clinical results of Ahmed glaucoma valve implantation in refractory glaucoma with adjunctive mitomycin C. Ophthalmic Surg Lasers. 2000;31(2):100-106.

91. Topouzis F, Coleman AL, Choplin N, et al. Follow-up of the original cohort with the Ahmed glaucoma valve implant. Am J Ophthalmol. 1999; 128(2):198-204

92. McDermott ML, Swendris RP, Shin DH, Juzych MS, Cowden JW. Corneal endothelial cell counts after Molteno implantation. Am J Ophthalmol. 1993;115(1):93-96.

93. Setala K. Corneal endothelial cell density after an attack of acute glaucoma. Acta Ophthalmol (Copenh). 1979;57(6):1004-1013.

94. Fiore PM, Richter CU, Arzeno G, et al. The effect of anterior chamber depth on endothelial cell count after filtration surgery. Arch Ophthalmol. 1989;107(11):1609-1611.

Clinical Ophthalmology

\section{Publish your work in this journal}

Clinical Ophthalmology is an international, peer-reviewed journal covering all subspecialties within ophthalmology. Key topics include: Optometry; Visual science; Pharmacology and drug therapy in eye diseases; Basic Sciences; Primary and Secondary eye care; Patient Safety and Quality of Care Improvements. This journal is indexed on Submit your manuscript here: http://www.dovepress.com/clinical-ophthalmology-journal
95. Kim CS, Yim JH, Lee EK, Lee NH. Changes in corneal endothelial cell density and morphology after Ahmed glaucoma valve implantation during the first year of follow up. Clin Experiment Ophthalmol. 2008;36(2):142-147.

96. Lee EK, Yun YJ, Lee JE, Yim JH, Kim CS. Changes in corneal endothelial cells after Ahmed glaucoma valve implantation: 2-year follow-up. Am J Ophthalmol. 2009;148(3):361-367.

97. Kim KN, Lee SB, Lee YH, Lee JJ, Lim HB, Kim CS. Changes in corneal endothelial cell density and the cumulative risk of corneal decompensation after Ahmed glaucoma valve implantation. $\mathrm{Br} J$ Ophthalmol. Epub 2015 Oct 27.

98. Koo EB, Hou J, Han Y, Keenan JD, Stamper RL, Jeng BH. Effect of glaucoma tube shunt parameters on cornea endothelial cells in patients with Ahmed valve implants. Cornea. 2015;34(1):37-41.

99. Schoenberg ED, Levin KH, Savetsky MJ, McIntire LU, Ayyala RS Surgical outcomes of DSAEK in patients with prior Ahmed glaucoma drainage device placement. Eur J Ophthalmol. 2013;23(6):807-813.

100. Riaz KM, Sugar J, Tu EY, et al. Early results of Descemet-Stripping and Automated Endothelial Keratoplasty (DSAEK) in patients with glaucoma drainage devices. Cornea. 2009;28(9):959-962.

101. Kim P,Amiran MD, Lichtinger A, Yeung SN, Slomovic AR, Rootman DS Outcomes of Descemet stripping automated endothelial keratoplasty in patients with previous glaucoma drainage device insertion. Cornea. 2012;31(2):172-175

102. Ide T, Yoo SH, Leng T, O’Brien TP. Subconjunctival Air Leakage After Descemet's Stripping Automated Endothelial Keratoplasty (DSAEK) in a Post-Trabeculectomy Eye. Open Ophthalmol J. 2009;3:1-2.

103. Ang GS, Varga Z, Shaarawy T. Postoperative infection in penetrating versus non-penetrating glaucoma surgery. Br J Ophthalmol. 2010; 94(12):1571-1576.

104. Rao A, Wallang B, Padhy TR, Mittal R, Sharma S. Dual infection by streptococcus and atypical mycobacteria following Ahmed glaucoma valve surgery. Semin Ophthalmol. 2013;28(4):233-235.

105. Stewart MW, Bolling JP, Bendel RE. Nocardia brasiliensis endophthalmitis in a patient with an exposed Ahmed glaucoma drainage implant. Ocul Immunol Inflamm. 2013;21(1):69-70.

106. Ranganath A, Hashim A. Late-onset endophthalmitis secondary to exposed glaucoma tube implant in a rare case of paediatric glaucoma. Case Rep Ophthalmol Med. 2011;2011:183647.

107. Gutierrez-Diaz E, Montero-Rodriguez M, Mencia-Gutierrez E, Fernandez-Gonzalez MC, Perez-Blazquez E. Propionibacterium acnes endophthalmitis in Ahmed glaucoma valve. Eur J Ophthalmol. 2001; 11(4):383-385.

108. Djodeyre MR, Peralta Calvo J, Abelairas Gomez J. Clinical evaluation and risk factors of time to failure of Ahmed glaucoma valve implant in pediatric patients. Ophthalmology. 2001;108(3):614-620.

109. Morad Y, Donaldson CE, Kim YM, Abdolell M, Levin AV. The Ahmed drainage implant in the treatment of pediatric glaucoma. Am J Ophthalmol. 2003;135(6):821-829.

110. Chen TC, Bhatia LS, Walton DS. Ahmed valve surgery for refractory pediatric glaucoma: a report of 52 eyes. J Pediatr Ophthalmol Strabismus. 2005;42(5):274-283.

111. Hong CH, Arosemena A, Zurakowski D, Ayyala RS. Glaucoma drainage devices: a systematic literature review and current controversies. Surv Ophthalmol. 2005;50(1):48-60.

PubMed Central and CAS, and is the official journal of The Society of Clinical Ophthalmology (SCO). The manuscript management system is completely online and includes a very quick and fair peer-review system, which is all easy to use. Visit http://www.dovepress.com/ testimonials.php to read real quotes from published authors. 